\title{
Implementation of renewable energy into the mining industry: A hybrid energy system
}

\author{
K. Pollack, J.C. Bongaerts \& C. Drebenstedt \\ Technical University Bergakademie Freiberg, Institute for Mining and Civil Engineering, Gustav-Zeuner \\ Straße, Freiberg
}

\begin{abstract}
An availability of technological solutions together with priorities to decarbonize the mining sector lead renewable energy (RE) to become an attractive energy source for the mining industry. Pilot projects were run in several countries. However, there is still a lack of knowledge on hybrid energy systems (HES) as an efficient technological solution towards integration of RE into the mining industry.

A HES is proposed to reduce energy cost for off-grid mines, which have much higher energy related costs then on-grid mines. In addition, replacing a part of diesel consumption by $\mathrm{RE}$ will reduce greenhouse gas (GHG) emissions and lead a mine towards sustainable operations. To take a decision in favor the integration of a HES into the mining industry globally, a technological feasibility of these systems is required. This work aims to provide a detailed analysis of a HES and a comparison of different technological solutions for powering a mine. The main results of this paper are a comparative analysis of a HES, microgrids, stand-alone systems as a technological solution to power the mining industry. Moreover, to discuss benefits and challenges of a HES and input parameters which have to be optimized in order to ensure a secure energy consumption of a HES.

This analysis of a HES can be generalized to all settings of mines, with specific practical implications especially for off-grid mines. This paper aims to attract attention of policy makers, decision makers, and experts on fossil fuel and RE technologies in order to give alternatives in powering the mining industry and can be applied worldwide.
\end{abstract}

Keywords: Mining Industry, Renewable Energy, Hybrid Energy System, Levelized Cost of Electricity (LCOE), $\mathrm{CO}_{2}$ Emissions

\section{INTRODUCTION}

The United Nations General Assembly in 2015 has been set up the sustainable development goals and the global goal on energy towards energy transition as follows: ensure universal, reliable, and affordable access to innovative energy services; increase substantially the share of $\mathrm{RE}$ in the worldwide energy mix; and double the worldwide rate of improvement in energy efficiency (Gielen, et al., 2019). To reach these targets, $\mathrm{CO}_{2}$ emission should be regulated under 1,100 gigatons; further, around $85 \%, 50 \%$, and $34 \%$ of global coal, natural gas, and oil reserves must not be combusted before 2050 (Shen, et al., 2018).

The highest proportion causing approximately $25 \%$ of all greenhouse gases (GHG) is emitted by electricity generation and heat, increasing the progress of RE sources is a valuable strategy for decreasing GHG emissions and thus resisting climate change (Jenniches 2018). RE has the capability to offer energy free of air pollutants and GHG by emitting (almost) zero of these gasses (Hussain, Arifen Aslam 2017).

According to the International Energy Outlook (Vidal 2018), with energy consumption by an industry about $40 \%$ of global energy consumption, about a quarter of the energy globally is used to produce mineral raw materials. In South Africa, the situation is similar, as the mining 
sector consumes more than $30 \%$ of total electricity generation and it supplies over $90 \%$ of all primary energy to generate electricity (Holman 2019).

The mining industry significantly depends on energy prices (Zharan and Bongaerts 2018). It appears, the share of energy costs accounts for 30-35\% of all operating costs of mining operations (Slavin, 2017), (Vyhmeister, et al., 2017), (Cormack, et al., 2017).

The recent years, PV modules have been the fastest developing RE technology. So a dieselPV hybrid energy system may produce about $1.8 \mathrm{GWh}$ of electricity per year, or about $60 \%$ of the mine's annual daytime power needs (Zharan, 2017). A hybrid PV-diesel system is more reliable in electricity production than a stand-alone diesel system and a stand-alone PV system Pollack, (Bongaerts and Drebenstedt 2020). Consequently, a HES can be an effective solution to enhance RE integration towards the mining industry.

Sustainable mining comprises many issues, such as engaging with communities towards establishing accountability and responsibility to enhance the industry's performance; establishing clear relationships with communities as a basic metric for investment decisions; decreasing the environmental impact in all phases of the mining operation; and finally striving for high levels of safety and health at work and maintain equally beneficial relationships with government authorities.

The research questions addressed in this paper are as follows:

- Can a HES be applicable in mining settings?

- What can be benefits and challenges of a HES to be implemented in mining operations?

- Which input parameters have to be optimized in order to ensure a secure energy consumption of a HES?

- What is a comparative analysis of a HES and conventional generator as two alternatives to power the mining industry?

\section{LITERATURE REVIEW}

By definition, any energy resource that is naturally regenerated over a short-time scale and derived directly from the sun (such as thermal, photochemical, and photoelectric), indirectly from the sun (such as hydropower, wind, and photosynthetic energy stored in biomass), or from other natural mechanisms and movements of the environment (such as tidal and geothermal energy) (Ellabban, Abu-Rub and Blaabjerg 2014) is considered as RE. The different RE technologies (e.g. hydro power, wind, solar photovoltaic (PV), geothermal energy, and others) are characterized by different performance characteristics and each among them requires specific location factors. Consequently, not each location is similarly appropriate (Jenniches 2018). Therefore, if this location is not attractive for RE, conventional energy sources still might be preferred, especially for on-grid mines.

A HES is a combined use of two or more energy technologies, such as photovoltaic, diesel, wind, and geothermal energy technologies (Mazzeo, et al. 2018), (Khan, Yadav and Mathew 2017). There are many types of a hybrid RE system, such as PV-gas, PV-diesel (Breyer, Goerig and Schmid 2011), diesel-PV-wind-batteries (Forough and Roshandel 2018), wind-diesel, PVwind, wind-fuel cell (Khan, Yadav and Mathew 2017), solar-wind (Yang, Lu and Zhou 2007). All of these HESs can be implemented in mining operations (Zharan and Bongaerts 2017).

Taking intermittent energy supply generated by renewables into account, it is still considered unfeasible to use a RE source without backup as a reliable energy source to power a mine. The potential temporal disparity of demand and supply raises two vital questions: how to serve demand at times when supply is rare, and how to deal with fluctuating RE at times when there is too much supply (Zerrahn, Schill and Kemfert 2018).

In the mining industry, characterized by a huge energy demand, strong safety requirements and a strong interaction and integration of operating sectors the first questionis more relevant. Thus, a combination of two or more energy sources (both renewables and non-renewables) so-called a HES can contribute to the issue of intermittency. This HES is completely sufficient and can be developed without exclusively dependence on a grid. 
Nevertheless, fossil fuel energy sources are still more reliable and suitable for industrial needs with high daily level of energy consumption. However, replacing conventional energy sources by RE is feasible for the mining companies nowadays and was done at several pilot projects (Zharan and Bongaerts 2017). On the one hand, the investigated topic has a strong business and scientific interest for project development from mining and RE companies. On the other hand, there is only a little contribution on scientific studies related to the integration of RE into the mining industry.

To our knowledge, some of them investigate perspectives on this topic. Particularly, (Nasirov and Agostini 2018) published a paper with particular focus on mining experts' perspectives on the determinants of solar technologies adoption in the Chilean mining industry. Additionally, a review of photovoltaic and wind power systems utilized in the mining industry was made by (Choi and Song 2017).

\section{RESEARCH METHODS AND MATERIALS}

This paper contains a comparative analysis of a HES. The description, benefits, barriers, and challenges of a HES are first discussed. Based on this, a deeper technological analysis of a HES is performed accounting for the different types of a HES. The input characteristics, optimization and control of a HES, and total cost parameters of a HES are discussed with a focus on mining settings. Additionally, case studies with particular focus on cost of a HES for various off-grid locations are compared applying the literature review method. Similarly, a detailed description of each technology as a part of a HES is given with the focus on the integration into the mining sector. The technologies observed are solar PV, wind, battery storage, and conventional generator systems (i.e. diesel engines, gas turbi nes). The summary and recommendations on a comparative analysis of a HES are given.

\section{RESULTS AND ANALYSIS}

A set of case studies (Zharan and Bongaerts 2017) for the mining industry shows, that a most applicable HES are stand-alone systems (so-called microgrids) for remote mining settings. By definition, a microgrid is a small-scale power grid consisting of distributed generation units, electrical or heat loads which operates as a single-controllable unit at the distribution voltage level, and energy storage systems (Mirsaeidi, Dong and Said 2018). On the one hand, a comparison of pros of on-grid and off-grid HESs including configurations of these systems is given as follows.

\section{Pros of an off-grid HES:}

- A HES can be either connected to many load centers or can be operated as a source of supply for one or two loads (Nema and Dutta 2012);

- A stand-alone system does not require a distribution system.

Pros of an on-grid HES (Nema and Dutta 2012):

- the stability of the overall system relies on grid in case of any technological problems of a HES;

- Feeding power to a grid in cases of redundant energy generation;

- Boosting the voltage and minimizing power cuts strengthens the grid.

On the other hand, due to intermittency of RE, it is not possible to replace completely fossil-based energy by RE in the mining industry (Pollack and Bongaerts 2019). Indeed, RE sources cannot usually meet required energy demand of a mine at all times.

However, there is a solution such as a HES combining RE and fossil fuel energy generating technologies towards avoiding intermittency of renewables. In this matter, a fossil fuel system considers as base-supply and backup system preventing a fluctuation of RE. In many remote 
applications, a diesel generator (DG) is used as a backup system (Jamshidi and Askarzadeh 2019) and usually used at the time, when energy generated from renewables cannot completely cover the mining needs or RE sources are not available.

Moreover, DG is usually added to a HES for its stabilization. However, a conventional generator system is still the main energy generating technology for electricity supply in off-grid mining operations. Table 1 shows a comparison of the benefits and challenges of a conventional generator.

A comparison of a HES and conventional generator can be seen in Table 2. This table shows the benefits and challenges of two energy generating technologies.

The shortcoming of the volatility of HES output can be avoided by adding battery storage to a HES. Further, a HES can be integrated to a new or as add-on to an already operating mine, thus, minimizing supplementary investments. Consequently, almost all challenges of a HES seen in Table 2 can be prevented, thus, giving to a HES more benefits to be integrated in mining settings comparing to a conventional generator.

A switch between different energy sources of a HES can lead to power outage (interruption in power supply). As defined by the Institute of Electrical and Electronics Engineers, an interruption means the complete loss of supply voltage or load current (Diboma and Tatietse

Table 1. Comparison of benefits and challenge of a conventional generator.

\begin{tabular}{ll}
\hline Benefit & Challenge \\
\hline $\begin{array}{l}\text { Improved power reliability, quality and protecting } \\
\text { against outages }\end{array}$ & $\begin{array}{l}\text { So far, the most common DG technologies operate } \\
\text { by diesel and gasoline-fueled engines depending on } \\
\text { diesel price fluctuation }\end{array}$ \\
$\begin{array}{ll}\text { Applicable for off-grid locations } \\
\text { Reduce project costs over time due to improving } \\
\text { of adjustment of additional demand and supply }\end{array}$ & $\begin{array}{l}\text { Utility competitive rates } \\
\begin{array}{l}\text { Provides standby power and peak power and } \\
\text { energy related costs savings }\end{array}\end{array}$ \\
$\begin{array}{l}\text { Avoiding a fuel disruption risks and high system } \\
\text { efficiency }\end{array}$ & $\begin{array}{l}\text { A fossil-based system produces the } \mathrm{CO}_{2} \text { emissions by } \\
\text { Utility competitive rates }\end{array}$ \\
\hline
\end{tabular}

Source: adapted from (National Renewable Energy Laboratory 2013)

Table 2. Benefits and challenges of a HES and conventional generator.

\begin{tabular}{|c|c|c|}
\hline \multirow[t]{2}{*}{ Benefit } & HES & Conventional generator \\
\hline & $\begin{array}{l}\text { Can be integrated into an existing mining } \\
\text { energy system } \\
\text { Reliable technology } \\
\text { Low GHG emissions impact } \\
\text { The instability of a system output can be } \\
\text { compensated by including a suitable energy } \\
\text { storage system (Behera and Nandkeolyar } \\
\text { 2017) }\end{array}$ & $\begin{array}{l}\text { Well-known established technology } \\
\text { Predicted energy supply }\end{array}$ \\
\hline \multirow[t]{2}{*}{ Challenge } & HES & Conventional generator \\
\hline & $\begin{array}{l}\text { An interruption in power supply require } \\
\text { stabilization } \\
\text { Updating or upgrading the equipment which } \\
\text { is presently applied in the distribution net- } \\
\text { works that require supplementary } \\
\text { investments } \\
\text { Relatively high initial cost }\end{array}$ & $\begin{array}{l}\text { High O\&M cost (Laquaniello, Montanari } \\
\text { and Salladinic 2017) } \\
\text { High fuel consumption due to ineffciency } \\
\text { under low load operation (Laquaniello, Mon- } \\
\text { tanari and Salladinic 2017) } \\
\text { High GHG emissions impact }\end{array}$ \\
\hline
\end{tabular}

Source: self-generated 
2013). For the mining industry, as a large energy consumer, a power outage can lead to unexpected expenses. Consequently, sizing, optimization and control, interaction and monitoring have to be carefully planned in order to avoid blackout of a HES.

Technological analysis of a HES. Usually, a HES is designed explicitly for each individual mine. To supply industrial load with reliable and stable power, the HES design is a very complex process and has to take all input characteristics into account, such as RE sources input parameters, total costs of a HES, and optimization and control of a HES. Overall these input characteristics influence on optimization of a system and storage and output of a HES. Figure 1 shows these input characteristics of a HES powering a mine.

Based on a study (Zharan and Bongaerts 2017) and depending on its location, the most feasible RE systems for a mine are solar PV, solar thermal, concentrated solar power (CSP), and wind. These RE systems can be grid-connected or used as a stand-alone system. For offgrid stand-alone systems, a conventional generator (operated by diesel or natural gas) is the stabilizing component of this system buffering the alternative supply of RE. In addition, in off-grid locations storage plays an important role for reliability of a HES. Nevertheless, a HES including storage is cost intensive, therefore, a question of reliability stays in conflict with total costs of a HES. On the one hand, the grid availability can be an option towards avoiding storage and making a HES project less cost intensive. On the other hand, a HES is economic relevant for off-grid mines where the energy costs are higher than for on-grid mines.

As summarized in Figure 1, the input characteristics of a HES require optimization in terms of costs, generation capacity, and volatility. Generation capacity of a HES depends on RE sources input parameters, such as solar irradiation, ambient temperature, and wind speed. The total costs of a HES consist of CAPEX, operating expenditures (OPEX), fuel cost, transmission cost, financing mechanism, and operation related losses. Finally, a volatility of a HES can be stabilized by optimization and control integrating monitoring of a system i.e.

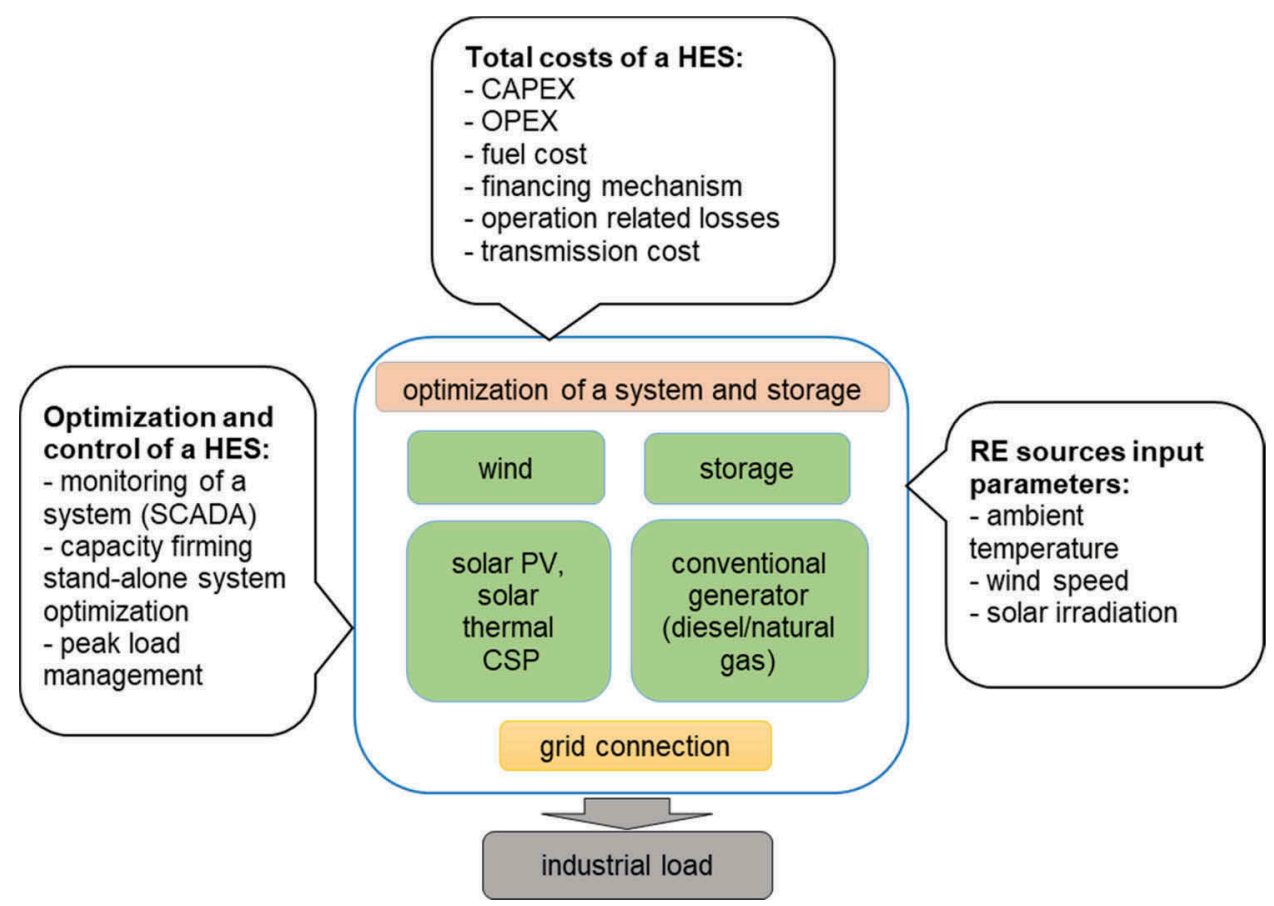

Figure 1. Input characteristics of a HES to be implemented in mining sector.

Source: self-generated 
Table 3. Analysis of each technology used to power a mine.

\begin{tabular}{|c|c|c|}
\hline Technology & Description of technology & Source \\
\hline $\begin{array}{l}\text { Conventional } \\
\text { DG/gas CC }\end{array}$ & $\begin{array}{l}\text { Ability to operate from } 100 \% \text { load down to } \\
\text { zero load } \\
\text { It ensures very fast response on required load } \\
\text { It is possible to declutch from the alternator } \\
\text { to stop } \\
\text { Can be used as a backup going in stable } \\
\text { reserves operations }\end{array}$ & $\begin{array}{l}\text { Zharan and Bongaerts 2017, Zhang, et al. } \\
2019\end{array}$ \\
\hline Wind & $\begin{array}{l}\text { Can be easy connected to a DG } \\
\text { Can be feasible solution at night-time sup- } \\
\text { porting a HES with additional power }\end{array}$ & Buonomano, et al. 2018 \\
\hline Solar PV & $\begin{array}{l}\text { Can be easy connected to a DG } \\
\text { A significant decrease in LCOE } \\
\text { No need of storage by using solar energy in } \\
\text { a direct way }\end{array}$ & Chaib, Achour and Kesraoui 2016 \\
\hline HES & $\begin{array}{l}\text { Secure and dynamic load balance between } \\
\text { variations in energy consumption and solar } \\
\text { intermittency } \\
\text { Diesel fuel savings } \\
\text { Simple in operation and maintenance } \\
\text { Reliable power supply } \\
\text { CAPEX of this HES is more than offset by } \\
\text { the direct fuel savings up to } 30-40 \% \text { per year, } \\
\text { assuming an usual } 24 \text { hour demand cycle. }\end{array}$ & $\begin{array}{l}\text { (Hybrid Power for Mining 2018), (Pollack } \\
\text { and Bongaerts 2019), (Zharan and Bon- } \\
\text { gaerts 2017) }\end{array}$ \\
\hline
\end{tabular}

Source: self-generated

a supervisory control and data acquisition (SCADA) control system, a stand-alone system optimization, peak load management, and capacity firming.

Every HES requires system optimization, system sizing, and economic modelling. These requirements can be reached using software dealing with a techno-economic feasibility of a HES, such as hybrid optimization of multiple energy resources (HOMER) microgrid software, hybrid optimization by genetic algorithms (HOGA) software (Zhang, et al. 2019), RETScreen, Dymola/Modelica, HYBRID 2, and Hybrid (DesignerPadron, et al. 2019). Furthermore, HYBRIDS is a Microsoft Excel spreadsheet-based application tool for a RE assessment and needs environmental data for each month of the year and daily average load (Anoune, et al. 2018). Each of this software can be used to optimize and model of a HES integrated into the mining sector. Further, various methods can be used to optimize a HES, such as nonlinear programming, linear programming, genetic algorithm, and others (Zhang, et al. 2019). Table 3 shows the analysis of each technology used to power a mine.

\section{CONCLUSION}

- A HES is widely applicable in existing and new energy systems in mining settings. Moreover, a HES has its benefits (i.e. improved power reliability, quality and protecting against outages, applicable for off-grid locations, and provides standby power and peak power and energy related costs savings) and challenges (i.e. relatively high initial cost, an interruption in power supply require stabilization), and is feasible to be implemented in mining operations. 
- A technological analysis of a HES has been done, and input characteristics of a HES have been analyzed. These characteristics require optimization in terms of costs, generation capacity, and reliability.

- Each HES requires the optimal sizing, cost optimization, and system stabilization process before applying into mining settings.

- Despite a noticeable increase in projects integrating a HES into the mining industry and environmental issues, conventional generator systems are still a dominant technology in mining operations providing a reliable energy supply. Therefore, a conventional generator is an essential part of a HES and can be used as a backup of each HES.

The further investigation will be focus on a technological analysis of storage facilities as a part of a HES with particular focus on off-grid mining settings.

\section{REFERENCES}

Anoune, K., Bouya M., Astito A., \& Abdellah, A. B. 2018. Sizing methods and optimization techniques for PV-wind based hybrid renewable energy system: A review. Renewable and Sustainable Energy Reviews 93: 652-673.

Behera, S. \& Nandkeolyar S. 2017. Analysis of isolated hybrid system for power supply to a remote island. Energy Procedia 117: 1040-1046.

Buonomano, A., Calise F., MD d'Accadia, \& Vicidomini M. 2018. A hybrid renewable system based on wind and solar energy coupled with an electrical storage: dynamic simulation and economic assessment. Energy. doi: 10.1016/j.energy.2018.05.006.

Chaib, A, Achour D., \& Kesraoui M. 2016. Control of a solar PV/wind hybrid energy system. Energy Procedia 95: 89-97.

Choi, Y., \& Song J. 2017. Review of photovoltaic and wind power systems utilized in the mining industry. Renewable and Sustainable Energy Reviews 75: 1386-1391.

Cormack, D., Wood M., Swart A., \& Davidse A. 2017. Renewables in Mining: Rethink, Reconsider, Replay. Deloitte Touche Tohmatsu, 27. Accessed 10 11, 2018. https://www2.deloitte.com/con tent/dam/Deloitte/global/Documents/Energy-and-Resources/gx-renewables-in-mining-final-reportfor-web.pdf.

Diboma, B.S, \& Tamo Tatietse, T. 2013. Power interruption costs to industries in Cameroon. Energy Policy 62: 582-592.

Ellabban, O., Abu-Rub, H., \& Blaabjerg, F. 2014. Renewable energy resources: Current status, future prospects and their enabling technology. Renewable and Sustainable Energy Reviews 39: 748-764.

Forough, A.B., \& Roshandel, R. 2018. Lifetime optimization framework for a hybrid renewable energy system based on receding horizon optimization. Energy 150: 617-630.

Gielen, D., Boshell, F., Saygin D., Bazilian, Morgan D., \& Wagner, N. 2019. The role of renewable energy in the global energy transformation. Energy Strategy Reviews 24: 38-50.

Holman, J. 2019. Big Eskom rate hike a 'death knell': MCSA. Mining Journal, 02 01. Accessed 02 04, 2019. https://www.mining-journal.com/events-coverage/news/1355580/big-eskom-rate-hike-deathknell-mcsa?utm_medium =email\&utm_campaign $=020419-074515-542 \% 20-\% 20 \mathrm{Doh} \% 20 \mathrm{Mint} \%$ 20launches $\% 20$ Simpsons $\% 20$ coins $\% 20$ Tethyan $\% 20$ on $\% 20 \mathrm{a} \% 20$ tear $\% 20$ Big $\% 20$ Eskom $\% 20 \mathrm{rate} \%$ 20hike $\% 20 \mathrm{a} \% 20$ dea.

Hussain, A., Arif, S. M., \& Aslam, M. 2017. Emerging renewable and sustainable energy technologies: State of the art. Contents lists available atScienceDirectRenewable and Sustainable Energy Reviews 71: $12-28$.

2018. Hybrid Power for Mining. Accessed 12 12, 2018. http://hybridpowerformining.com.

Jamshidi, M, \& Askarzadeh, A. 2019. Techno-economic analysis and size optimization of an off-grid hybrid photovoltaic, fuel cell and diesel generator system. Sustainable Cities and Society 44: 310-320.

Jenniches, S. 2018. Assessing the regional economic impacts of renewable energy sources-A literature review. Renewable and Sustainable Energy Reviews 93: 35-51.

Khan, M. J., Yadav, A. K., \& Mathew, L. 2017. Techno economic feasibility analysis of different combinations of PV-Wind-Diesel-Battery hybrid system for telecommunication applications in different cities of Punjab, India. Renewable and Sustainable Energy Reviews 76: 577-607.

Laquaniello, G., Montanari, W., \& Salladinic, A. 2017. Standalone CSP-DG system for electrification of remote areas and desalinated water supply. Solar Energy 157: 1056-1063. 
Mazzeo, D., Oliveti, G., Baglivo, C., \& Congedo, P.M. 2018. Energy reliability-constrained method for the multi-objective optimization of a photovoltaic-wind hybrid system with battery storage. Energy. doi: 10.1016/j.energy.2018.04.062.

Mirsaeidi, S., Dong, X., \& Said, D. M. 2018. Towards hybrid AC/DC microgrids: Critical analysis and classification of protection strategies. Renewable and Sustainable Energy Reviews 90: 97-103.

Nasirov, S., \& Agostini, C. A. 2018. Mining experts' perspectives on the determinants of solar technologies adoption in the Chilean mining industry. Renewable and Sustainable Energy Reviews 95: 194-202.

National Renewable Energy Laboratory. 2013. OpenEI. 3 7. Accessed 11 7, 2018. https://openei.org/wiki/ Distributed_Generation.

Nema, P., \& Dutta, S. 2012. Feasibility Study of 1 MW Standalone Hybrid Energy System: For Technical Institutes. Low Carbon Economy 3: 63-68.

Padron, I., Avila, D., Marichal, G. N., \& Rodriguez, J. A. 2019. Assessment of Hybrid Renewable Energy Systems to supplied energy to Autonomous Desalination Systems in two islands of the Canary Archipelago. Renewable and Sustainable Energy Reviews 101: 221-230.

Pollack, K., \& Bongaerts, J. C. 2019. Mathematical Model on the Integration of Renewable Energy in the Mining Industry. International Journal of Energy Sector Management.

Slavin, A. 2017. New renewable energy for mine project - LAMGOLD Essakane to benefit from largest hybrid plant in Africa (Case Study). Energy and Mines, 03 06: 547-559.

Shen, W., Qiu, J., \& Dong, Z. 2018. Electricity network planning targeting Low-Carbon energy transition. Global Energy Interconnection 1 (4): 487-499.

Yang, H., Lu, L., \& Zhou, W. 2007. A novel optimization sizing model for hybrid solar-wind power generation system. Solar Energy 81: 76-84.

Vidal, O. 2018. Energy Requirements of the Mining and Metallurgical Industries. Mineral Resources and Energy 27-52.

Vyhmeister, E., Munoz, C. A., Miquel, J. M. B., Moya, J. P., Guerra, C. F., Mayor, L. R., GodoyFaundez, A., et al. 2017. A combined photovoltaic and novel renewable energy system: An optimized techno-economic analysis for mining industry applications. Journal of Clenear Production 149: 999-1010.

Zerrahn, A., Schill, W.-P., \& Kemfert, C. 2018. On the economics of electrical storage for variable renewable energy sources. European Economic Review 108: 259-279.

Zhang, W., Akbar M. I, Rosen, M. A., \& Liu, J. 2019. Sizing a stand-alone solar-wind-hydrogen energy system using weather forecasting and a hybrid search optimization algorithm. 15.

Zharan, K. 2017. Renewable Energy for the Mining Industry: Trends and Developments. In: L. a. Matasci, ed. Boosting Resource Productivity by Adopting. St.Galen: A World Resources Forum Production, p. 429 Energy Conversion and Management 180: 609-621.

Zharan, K., \& Bongaerts, J. C. 2017. Decision-making on the integration of renewable energy in the mining industry: A case studies analysis, a cost analysis and a SWOT analysis. Journal of Sustainable Mining 16 (4): 162-170.

Zharan, K., \& Bongaerts, J. C. 2018. Survey on Integrating of Renewable Energy into the Mining Industry. Journal of Environmental Accounting and Management 6 (2): 149-165. 